Transportation Research Forum

Industry Issue Paper: Cross-Cultural Factors and Corporate Governance Transparency in Global Airline Strategic Alliances

Author(s): Catherine C. Giapponi and Carl A. Scheraga

Source: Journal of the Transportation Research Forum, Vol. 46, No. 2 (Summer 2007), pp. 101-122

Published by: Transportation Research Forum

Stable URL: http://www.trforum.org/journal

The Transportation Research Forum, founded in 1958, is an independent, nonprofit organization of transportation professionals who conduct, use, and benefit from research. Its purpose is to provide an impartial meeting ground for carriers, shippers, government officials, consultants, university researchers, suppliers, and others seeking exchange of information and ideas related to both passenger and freight transportation. More information on the Transportation Research Forum can be found on the Web at www.trforum.org. 


\title{
Cross-Cultural Factors and Corporate Governance Transparency in Global Airline Strategic Alliances
}

\author{
by Catherine C. Giapponi and Carl A. Scheraga
}

This paper argues that a critical dimension in understanding the factors that inhibit the effectiveness and benefits of airline alliances is corporate transparency. Specifically, the issue of transparency in corporate governance is considered. Corporate governance is the set of institutional arrangements affecting corporate decision making, and deals with the relationship among various participants in determining the direction and performance of corporations.

However, airline strategic alliances span an array of national cultures which influence the development of such relationships. The impact of national culture as a determinant of governance transparency is also investigated in this paper. This study draws on the literature which examines the impact of national culture on international joint ventures and governance systems. National cultures are described by Hofstede's five dimensions of power distance, uncertainty avoidance, individualism, masculinity, and temporal orientation.

Governance transparency is investigated by the examination of corporate annual reports. Thus, this study investigates not only the level of corporate governance transparency demonstrated by participants in each of the three major airline alliances, but the relationship between said governance transparency and the cultural identity of each of the participants.

\section{INTRODUCTION AND FOCUS OF CURRENT STUDY}

Strategic alliances have become an increasingly important part of the corporate strategic planning process. Within the international airline industry, the 1990s witnessed the emergence of three global multi-carrier alliances: Star, oneworld, and Skyteam. These three alliances are comprised of airlines spanning numerous national cultures. However, while these alliances have been successful in achieving incremental revenue enhancements, they have been less so with regard to the achievement of economic synergies through cost cutting. This study provides an integrated framework for understanding the organizational drivers of these economic synergies, specifically those associated with corporate governance transparency. The rationale for focusing on these specific drivers and their importance is discussed here in detail. Furthermore, the impact of specific characteristics of national cultures on corporate governance transparency is empirically tested.

A recent study by the Boston Consulting Group done by Cools and Roos (2005) provided a sobering prognostication regarding the future of strategic alliances in the airline industry. Strategic alliances in this industry were a response to regulatory and cultural barriers that inhibited airlines from pursuing merger and acquisition strategies that were consistent with the economic logic of consolidation. High fragmentation in the airline industry had resulted in excess capacity and poor economic performance. Consolidation would have provided several opportunities. First, operational synergies provide opportunities for cost rationalization. Second, network synergies can reduce costs and improve asset utilization. Finally, consolidation can provide platforms for future growth.

Because of the regulatory and cultural barriers noted above, airlines have pursued the alternative strategy of global alliances. Consumers have directly benefited from these alliances through increased frequency of flights, better connectivity between destination points, and the consolidation of frequent flyer programs. The Boston Consulting Group study suggests, however, that the extra revenue that has resulted from these consumer benefits has been almost fully realized or "harvested" 
(Cools and Roos 2005, 18). The study notes that while cost cutting is long overdue, the alliances have not been effective in facilitating tougher cost synergies.

The study also notes four major reasons for the inability of airline strategic alliances to provide further consolidation in the industry. First, there are asymmetric benefits to airlines that make the initial investments necessary for cost synergies. That is, there is no guarantee that "the airline that invests the most will receive the greatest benefits" (Cools and Roos 2005, 19). Thus, airlines are hesitant to make these investments. Second, such investments represent a commitment to an alliance that is irreversible. Airlines perceive this as a reduction in strategic flexibility even though such flexibility has been used to justify the logic of strategic alliances. Again, airlines are hesitant to make the necessary investments. Third, a significant engagement in a strategic alliance is often seen as erosion in option value. Company executives have less freedom to choose alternative strategies in shaping the destinies of their airlines. Finally, the effectiveness of global strategic airline alliances has been hampered by cumbersome decision making. Often, every airline in an alliance has an equal vote regardless of size or importance. Thus, operational consolidations have typically been bilateral in nature, involving only two members of an alliance rather than all members.

The strategy of collaboration is often perceived as having significant costs that may outweigh any possible benefits. Whipple and Frankel (2000) suggest that the most important factors influencing the success of alliances are trust, senior management support, and the ability to meet performance expectations, clear goals, and partner compatibility. Koza and Levin (1998), as well as Whipple and Frankel (2000), argue that different alliance partners have different views on trust and what it entails. Mutual trust is best fostered when the structure of an alliance closely supports the intent of the alliance. Thus, alliances must be carefully and thoroughly planned and controlled so that trust and defined boundaries are not violated (Spekman et al. 1998; Whippel and Frankel 2000). Participants in an alliance being formed must agree to the contribution of each member and the sharing of profits. This is not always easily accomplished because the reality is that every firm has specific, if not idiosyncratic, objectives that it wishes to achieve (Lewis 1990). Therefore, alliance members must have a clear understanding of what each of them needs to invest in the strategic alliance as well as what each can expect in return. In addition to a commonality of goals among strategic alliance participants, there must also be compatibility of corporate cultures (Spekman et al. 1998).

This latter point is more specifically addressed in a model proposed by Simon and Lane (2004). They argue that the existence of shared complementary resources between strategic alliance partners is not sufficient to allow for alliance effectiveness. In addition to these resources, the factors that allow the employees of alliance members to interact with each other in order to share, combine, and leverage such complementarities are critically important. In defining these factors, they focus on differences in organizational, professional, and national culture. They suggest that the "more salient the cultural differences are to the value-creating activities of an alliance, the more disruptive those differences will be on the alliance's value-creating activities” (Simon and Lane 2004, 315).

The discussion below will illustrate how the concept of netchains, which incorporate the attributes of supply chains and networks, can be used to describe airline strategic alliances. However, the work done by Larson (1992) is critical to this study. She found that strategic alliances, which by nature are networks, have critical factors for success beyond economic incentives and mutually beneficial strategic rewards. These include a history of prior personal relations and knowledge of network partners' reputations that lead to a commitment to a mutual orientation. Such an orientation requires knowledge of potential partners' businesses and a respectful understanding of the interests of others.

Spekman et al. (1998) suggest that strategic alliance cooperation occurs at the boundaries of each of the alliance participants. If the firm is the total set of inter-structured activities in which it is engaged and over which it has discretion to initiate, maintain, or end behaviors, then the boundary of the organization is located where its discretion ends and that of another begins. Thus, one can also define the boundary of the strategic alliance itself. This definition establishes the "permeability" 
between firms, that is, the extent to which members of the strategic alliance allow skills, information, and technology to flow from one firm to another,

Lewis (1990) argues that these alliance boundaries, which mark the points of contact among strategic alliance participants, are characterized by two phenomena: formal and informal interfaces. Formal interfaces include the control and reporting mechanisms that structure inter-firm interactions. These mechanisms may include the structuring of boards of directors and other management personnel, the content of equity agreements, contracts joint development agreements, and the execution of operational integration. At the same time, informal interfaces, as noted by Spekman et al. $(1998,759)$, "reinforce personal commitment and trust, provide access to personal information and contacts, and foster the development of informal networks that allow managers to accomplish various tasks at different levels of the organization.”

For all of the reasons noted above, this study argues that corporate transparency among strategic alliance partners is critically important. We use the definition of corporate transparency developed by Bushman et al. (2004). Corporate transparency is the availability of firm-specific information to those outside the firm. Specifically, the study focuses on the dimension of corporate transparency embraced by corporate governance disclosure. Corporate governance is the set of institutional arrangements affecting corporate decision making, and deals with the relationship among various participants in determining the direction and performance of corporations (Monks and Minnow 1995). Corporate governance transparency directly impacts relationship transparency - a concept of considerable interest in the supply chain management literature. Relationship transparency can be defined as an individual party's subjective perception of being informed about relevant actions and properties of the other party in the interaction (Eggert and Helm 2003). Greater relationship transparency in a strategic interaction leads to more favorable behavioral intentions on the part of participants in such an interaction.

Governance transparency is investigated by the examination of corporate annual reports. The latest available reports of all the members of the three major airline alliances - Star, oneworld, and Sky Team - are utilized. There is analytical precedent for this approach (see Bushman, Piotroski, and Smith 2004). An extension of the conceptual and measurement scheme utilized by Bushman et al. (2004) is employed in this study. Furthermore, the seminal work by Gray (1988) and subsequent research has demonstrated a relationship between a country's cultural profile as measured by Hofstede's (1980) dimensions and the level of disclosure/transparency in the annual corporate reports of firms in that country. The importance of cross-cultural factors is discussed in detail below. Thus, this study investigates not only the level of corporate governance transparency demonstrated by participants in each of the three major airline alliances, but the relationship between said governance transparency and the cultural identity of each of the participants.

\section{NETCHAINS AND TRANSPARENCY}

The two concepts of netchains and transparency are very relevant to a description of the interrelationships found in strategic alliances in the airline industry. Lazzarini, Chaddad, and Cook $(2001,7)$ define a netchain as a "set of networks comprised of horizontal ties between firms within a particular industry or group, such that these networks (or layers) are sequentially arranged based on the vertical ties between firms in different layers." Suppliers, manufacturers, distributors, and customers typically represent these different layers, linked by supply chains. Furthermore, "netchain analysis explicitly differentiates between horizontal (transactions in the same layer) and vertical ties (transactions between layers), mapping how agents in each layer are related to each other and to agents in other layers.”

There are sources of value in netchains, as discussed by Lazzarini, Chaddad, and Cook (2001), which are much akin to the sources of value in airline strategic alliances. The supply chain aspects of netchains underpin the advantages of airline strategic alliances that are traditionally discussed in the literature. Supply chain analysis focuses on production and optimization. Supply chain 
structures also help to optimize transactions costs that are incurred when using the market system. Not surprisingly, airline strategic alliances have focused on economies of scale, increased traffic density, and economies of scope, as well as the improvement in service quality and convenience.

Of more interest to the current study are the network aspects of netchains that have value impacts on organizations with regard to social structure, learning, and network externalities. In the first case, networks give rise to a social structure, which influences individual or collective behavior, and by extension, performance. This social structure influences the resources that accrue to an individual or group because of their location in the network (Adler and Kwon 1999, 4).

The discussion in the literature as to the optimal structure of networks, which are most likely to yield social structure benefits, has divided itself between proponents of "dense" networks and those of "sparse" networks. Dense networks are defined as those where network members are extensively connected with each other (Coleman 1990) and have repeated, relational exchanges (Nelson 1989; Krackhardt 1992). Such dense networks promote trust, the development of social norms, and resultant cooperation. In addition, intra-industry coalitions may emerge that possess the power to negotiate better terms of trade with firms in other industries or netchain layers as well as modifying the degree of competition within coalition industries (Pfeffer and Nowak 1976; Galaskiewicz 1985; Lane and Bachmann 1996).

Proponents of sparse networks with weak ties and occasional market-like transactions between organizations suggest that such relationships generate new information and diversity, both of which are critical for generating innovations that create benefits and opportunities for members of the network. The "looseness" of these relationships is important in that the temptation to be "locked into" resources which are highly specialized and may be of only temporal value (Grabher 1993; Uzzi 1997; Afuah 2000).

Additionally, networks provide opportunities for learning. Membership in a network allows for the sharing of specific and specialized knowledge developed by individual organizations, thus creating the diversity of information noted above (Demsetz 1988; Zenger and Poppo 1999). Learning in a network may also give rise to "co-specialization." The process of co-specialization reflects the combining of individual capabilities of network members to develop network-wide routine practices (Nelson and Winter 1982; Kogut and Zander 1992). However, co-specialization may, as in the case of dense networks, lead to a reduction in the opportunities that can be exploited by individual network members and may inhibit their ability to react to new external knowledge (Leonard-Barton 1995).

Finally, network externalities may provide "increasing returns to adoption” (Katz and Shapiro 1985; Arthur 1989). Network externalities provide the opportunity for such an effect in both a direct and indirect manner. Direct increasing returns to adoption occur when the adoption of a technology or process by multiple organizations allows for increased benefits for all users. Furthermore, greater adoption of a technology or process allows for more experience to be gained with that technology leading to greater improvement in said technology or process. Indirect increasing returns to adoption occur when the technologies, products, or processes of network members can be used together, that is, they exhibit complementarities.

An example of an area of technological concern for airline alliance partners, as noted by Cools and Roos (2005), which lends itself to the benefits of increasing returns to adoption, is information technology. They observed that information systems, even among alliance partners, are still fragmented, idiosyncratic, and backward. Consolidation would benefit all alliance partners. Yet, such consolidation has not made significant progress. Another area that would benefit from increasing returns to adoption is that of joint procurement with regard to high cost items, such as aircraft and spare parts, or more mundane items, such as food and fuel.

Hofstede $(2003,18)$ defines transparency in a netchain as "the extent to which all the netchain's stakeholders have a shared understanding of, and access to, the product-related information that they request, without loss, noise, delay and distortion.” Loss occurs when a netchain participant does not transmit information, while noise implies that a netchain participant adds non-relevant data to the 
body of accumulated information. Delay occurs when a netchain participant delays information, and distortion implies that a netchain participant changes information either by accident or on purpose. He further notes that a precondition for netchain transparency is a shared understanding that may include: a shared language, shared interpretation of key concepts, shared standards for product quality, shared reference information models, and shared technological infrastructure.

Transparency allows the netchain to be more responsive to (unanticipated) external events. Again, Hofstede $(2003,18)$ notes that increased responsiveness allows producers to anticipate market demand accurately; netchain participants to plan their capacity accurately; netchain participants to readily perceive defects in quality control and to readily identify the source of such problems; and customers to identify the quality- and value-related attributes of a product or service.

\section{NATIONAL CULTURE AND TRANSPARENCY}

Hofstede (2003) provides an interesting discussion of the relationship between national culture and network transparency. His father (Hofstede 1980; Hofstede and Bond 1988) empirically derived five dimensions of culture: individualism versus collectivism, power distance, masculinity versus femininity, uncertainty avoidance, and short-term versus long-term orientation. Numerous replication studies utilizing these dimensions have established their validity and reliability (see Sondergaard 1994). Furthermore, these dimensions have found widespread use in many areas of behavioral and organizational research. In recent research, his cultural dimensions have been related to perspectives on and determinants of business ethics (Schepers 2006; Su 2006; Smith and Hume 2005; Swaidan and Hayes 2005), consumer decision-making and advertising (Mikhailitchenko and Whipple 2006; Bang, Raymond, Taylor, and Moon 2005; Leo, Bennett, and Hartel 2005; Malai and Speece 2005; Yoo and Donthu 2005), new product development (Garrett, Buisson, and Yap 2006; Dwyer, Mesak, and Hsu 2005), international negotiations (McGinnis 2005; Rammal 2005), joint ventures (Ritchie and Eastwood 2005), management control (Garg and Ma 2005; Lere and Portz 2005), information technology (McCoy, Everard, and Jones 2005), total quality management (Jabnoun and Khafaji 2005), industrial relations (Black 2005), leadership (Littrell and Valentiri 2005), and incentive preferences (Rehu, Lusk, and Wolff 2005).

The individual in an individualistic culture is independent; so too are organizations in such a culture. A market model governs networks with transactions regulated by contracts or informal deals, but with no ulterior motives to a particular transaction. Collectivist cultures would view networks as extended families. Individuals in these networks are bound to each other by life-long links of loyalty and obligation, and there is no need for contracts. There is a clear distinction between the in-group and the out-group. While netchains may be reconfigurable in individualistic cultures, they are typically not so in collectivistic ones. Providing information to members of the out-group is seen as morally wrong. Lying is not necessarily seen as inherently problematic. It is acceptable, in fact, morally acceptable, to favor friends over others even though this might be labeled as corruption in individualistic cultures.

Cultures of high power distance also provide a problematic environment for netchains. In such cultures, delegation of authority is problematic which, in turn, impedes transparency. Providing information to third parties not controlled by senior authorities may not be acceptable. Transparency in netchains requires strategic alliance partners to yield some of their autonomy, which may be difficult in rigid hierarchies.

Feminine cultures would be more likely to capitalize on the social and learning structures of netchains. In such cultures, talking is preferred over fighting and cooperation is preferred over competition. Masculine cultures, by contrast, favor fierce competition with a basic distrust held between individuals. Leader firms in a strategic alliance would seek to dominate less dominant partners in the alliance.

Cultures that demonstrate high uncertainty avoidance exhibit a preference for strict dogmas and principles. For organizations in such cultures, rules are important as is strict adherence to tradition. 
Cooperative relationships, therefore, may exhibit conflict over agreements and exceptions. Low uncertainty avoidance cultures will have no problem changing deadlines and contracts in response to situational changes. Finally, organizations in cultures with a short-term orientation pursue shortterm returns, as opposed to those realized in the long run. Long-term agreements are thus fragile, often replaced by transactions in short-term spot markets.

\section{NETCHAINS AND AIRLINE STRATEGIC ALLIANCES}

Oum et al. (2000) provide an extensive discussion of the reasons for airline strategic alliances. These include the expansion of seamless service networks, traffic between alliance partners, cost efficiencies, the improvement of service quality, co-marketing advantages, and the reinforcement of market power with cooperative pricing. As suggested above, these motivations represent the supply chain aspects of netchains.

It was also noted that of greater interest to this study were the network aspects of netchains. Doganis (2001) points out that airline agreements fall along a spectrum that ranges from interline agreements, or joint frequent flyer programs, to joint ventures, where partners come together to operate a business. KLM has been particularly active in the latter area. In 1998, KLM and Alitalia announced their intent to operate their passenger and cargo services as two integrated joint ventures. More recently, KLM and Air France have consolidated their operations through the first large international merger of two airlines. The two airlines are owned by a common parent/holding company, Air France-KLM; but, at the same time, will retain and operate under their own brand names from their home bases of operation in Paris and Amsterdam. The new holding company will be managed by the joint structure of the Strategic Management Committee, consisting of four French and four Dutch members.

Doganis (2001) further points out that airline strategic alliances fall along a similar spectrum. The simplest alliances, covering a limited number of routes or city pairs, involve special pro-rate (the prices airlines agree to charge for carrying each other's passengers) agreements and/or code sharing. At the other end of the spectrum are the global alliances that include schedule coordination, joint sales offices and ground handling, combined frequent flyer programs, and joint maintenance activities. Sometimes such alliances include mutual equity stakes. Global strategic alliance partners may also have regional alliances, thus making the global alliance a very complex structure. Ultimately, global strategic airline alliances may move towards franchising, common branding, joint cargo and passenger services ventures, and, finally, full mergers. To facilitate such undertakings, airlines will need to understand the network aspects of netchains in order to fully exploit the benefits of these opportunities.

\section{THE USE OF CORPORATE ANNUAL REPORTS}

Stanton and Stanton (2002) provide a comprehensive overview of the use of corporate annual reports in the research literature. Corporate annual reports are the means by which companies communicate with their various constituencies and stakeholders. However, they are more than simply formal documents that are produced in response to mandatory corporate reporting requirements. Hopwood $(1996,55)$ suggests that corporate annual reports have the main purpose of constructing a "particular visibility and meaning" as opposed to "what was there." In discussing financial accounting, Hines $(1988,257)$ elaborates on this notion: "We create a picture of an organization, or the 'economy', whatever you like, and on the basis of that picture (not some underlying 'real' reality of which no one is aware), people think and act. And by responding to that picture of reality, they make it so; it becomes 'real in its consequences.' And what is more, when people respond to that picture, and the consequences occur, they see it as proof of our having correctly conveyed reality."

Thus, as Stanton and Stanton (2002) argue, researchers use corporate annual reports to view the “visibilities and meanings” noted by Hopwood above. Anderson and Imperia (1992), Bekey (1990), 
and Neu et al. (1998) provide interesting examples of how corporate annual reports communicate the personality and philosophy of the firm, market the firm, and present a particular organizational image. Stanton and Stanton (2002) compile a detailed listing of the perspectives in annual reports that have been studied by researchers. These include image management, marketing, organizational legitimacy, political economy, and accountability. More specifically, there may be an inherent tension between the presentation of corporate legitimacy and social responsibility and that of political economy and image management and marketing. Keasey and Wright (1993) argue that this tension between perspectives affects the quality of communication with regard to accountability and governance.

The use of annual reports for studies related specifically to disclosure has been well documented. Botosan (1997, 329) states that "although the annual report is only one means of corporate reporting, it should serve as a good proxy for the level of voluntary disclosure provided by a firm across all disclosure avenues." Lang and Lundholm (1993) note that annual report disclosure levels are positively correlated with the amount of disclosure provided via other media. Knutson $(1992,7)$ states that "at the top of every analyst's list (of financial reports used by analysts) is the annual report to shareholders. It is the major reporting document and every other financial report is in some respect subsidiary or supplementary to it.” Patel and Dallas $(2002,6)$ suggest that the use of annual reports "facilitates analysis and comparison of companies around the globe."

Gray (1988) has developed a framework that links Hofstede's dimensions of culture and the development of accounting systems, the regulation of the accounting profession, and attitudes towards financial management and disclosure. He suggests four accounting value dimensions that influence a nation's financial reporting practices. These are: professionalism versus statutory control, uniformity versus flexibility, conservatism versus optimism, and secrecy versus transparency. This last dimension is of particular interest to this study. Gray $(1988,8)$ defines secrecy as "a preference for confidentiality and the restriction of disclosure of information about the business only to those who are closely involved with its management and financing as opposed to a more transparent, open and publicly accountable approach.” Furthermore, he hypothesizes (p. 11) that the higher a country ranks in terms of uncertainty avoidance, power distance, and masculinity, and the lower it ranks in terms of individualism, the more likely it will rank high in terms of secrecy.

High uncertainty avoidance implies a preference for secrecy because of the need to restrict information disclosures in order to avoid conflict and competition. A high ranking on power distance, associated with the need to preserve inequalities in power, would also be consistent with a preference for secrecy. A collectivistic orientation with a sense of responsibility to insiders, as opposed to those external to the firm, would also be consistent with secrecy. Feminist cultures that emphasize the quality of life, people, and the environment will tend to be more transparent with regard to information.

\section{RESEARCH DESIGN}

A qualitative analysis of the intensity of governance disclosure was conducted through the examination of the most recent corporate annual reports filed by the full members of the three major airline alliances, Star, oneworld, and SkyTeam. The Star Alliance members examined in the study included Air Canada, Air New Zealand, ANA, Austrian, LOT Polish Airlines, Lufthansa, SAS, Singapore Airlines, South African Airlines, Swiss, TAP Portugal, Thai, United, U.S. Airways, and Varig. It should be noted that annual reports for two members of the Star Alliance, Asiana and BMI, were not available. These companies were, therefore, excluded from the research. The members of the oneworld Alliance included in the study consisted of Aer Lingus, American Airlines, British Airways, Cathay Pacific, Finnair, Iberia, LAN, and Qantas. The SkyTeam Alliance members studied included Aeroflot, Aero Mexico, Air France, Alitalia, Continental, Czech Airlines, Delta, Korean Air, and Northwest Airlines. The airlines in this study and their ICAO designators are listed in Table 1. 
For purposes of the study, governance transparency was defined as the disclosure of governance information that can be used to hold executives/officers, boards of directors, and majority owners accountable to investors, stakeholders, and the public. Governance transparency, therefore, was measured based on the specific disclosure of information related to corporate executives, board of directors, and shareholders provided in each company's annual report, or $10 \mathrm{~K}$ when issued in lieu of an annual report. The measurement framework is an extension of the governance transparency variables used in research conducted by Bushman, Piotroski, and Smith (2004) and Christopher and Hassan (2005). The list of disclosure items adopted for purposes of this study was extended to include additional governance attributes identified in the Patel and Dallas (2002) study of transparency and disclosure. A total of 29 disclosure items were used (see Table 2 for a complete list). Each company was rated based on the actual disclosure of each piece of information (see Tables 3A, 3B, and 3C). They were categorized into two groups: those that disclosed $50 \%$ or more of the governance items and those that disclosed less than $50 \%$ of the items. The $50 \%$ criterion was utilized as this was the intra-group division suggested by the data.

The relationship between Hofstede's cross-cultural factors (1980) and governance disclosure was examined using the Tukey-Kramer method (Tukey 1953; Kramer 1956). The fifth factor of time orientation was not included because the Hofstede-Bond (1988) study provided data for only 23 countries, which represented a very small sub-sample of the strategic alliances. In the current study, the problem of testing differences in means was complicated by the fact that the sub-samples were of unequal size. These unequal cell sizes required that an extension of the test proposed by Tukey $(1952,1953)$ be used. The original Tukey test (1952) was designed specifically for pairwise comparisons based on the studentized range and controls the maximum experiment-wise error rate (MEER) when the sample sizes are equal. Tukey (1953) and Kramer (1956) independently proposed a modification for unequal cell sizes. The Tukey-Kramer method, as used in this study, has fared extremely well in Monte Carlo studies (Dunnett 1980). Additionally, Hayter (1984) provides a proof that the Tukey-Kramer procedure controls the MEER.

Specifically, for two groups $y_{i}$ and $y_{j}$, with $n_{i}$ and $n_{j}$ observations in each group respectively and $s$ being the root mean square error based on $v$ degrees of freedom, their means $\overline{y_{i}}$ and $\overline{y_{j}}$ are considered significantly different by the Tukey-Kramer criterion if:

$$
\left|\bar{y}_{i}-\bar{y}_{j}\right| / s \sqrt{\left(1 / n_{i}+1 / n_{j}\right) / 2} \geq q(\alpha ; \kappa, v)
$$

where $q(\alpha ; \kappa, v)$ is the $\alpha$-level critical value of a studentized range distribution of $\kappa$ independent normal random variables with $v$ degrees of freedom. The software utilized is the GLM (General Linear Model) procedure in SAS (2002), which calculates significance for the Tukey-Kramer statistic at the $5 \%$ level.

\section{RESULTS}

The intensity of governance disclosure varied across companies and across airline alliances. Disclosure was strongest among the members of the oneworld Alliance, with $88 \%$ of the members achieving a disclosure rate of over 50\% (see Table 4). The Star Alliance ranked second in terms of overall governance disclosure, with $67 \%$ of its members disclosing over $50 \%$ of the governance information. SkyTeam had the lowest overall ranking, with $56 \%$ of its members disclosing over $50 \%$ of the governance items. SkyTeam is the youngest of the airline alliances, launched in 2000, two years after the founding of oneworld and three years after the launch of Star Alliance. Governance transparency is one dimension of corporate transparency and, given the importance of transparency in building strong alliance relationships, SkyTeam's low disclosure rate may prove problematic.

Table 4 also displays Hofstede's (1980) indices for each of the four dimensions of uncertainty avoidance (UA), power distance (PD), individualism (IND), and masculinity (MAS). High values for each of these four indices would indicate a national culture characterized by high 
Table 1: Airline Alliances Members and ICAO Designators

\begin{tabular}{lc}
\hline Airline & ICAO Designator \\
\hline Aeroflot & AFL \\
Aer Lingus & EIN \\
Aeromexico & AMX \\
Air Canada & ACA \\
Air France & AFR \\
Air New Zealand & ANZ \\
Alitalia & AZA \\
All Nippon Airways & ANA \\
American Airlines & AAL \\
Asiana & AAR \\
Austrian Airlines & AUA \\
British Airways & BAW \\
Cathay Pacific Airways & CPA \\
Continental Airlines & COA \\
Czech Airlines & CSA \\
Delta Airlines & DAL \\
Finnair & FIN \\
Iberia Airlines & IBE \\
Korean Airlines & KAL \\
LAN & LAN \\
LOT Airlines & LOT \\
Lufthansa & DLH \\
Northwest Airlines & NWA \\
Qantas Airways & QFA \\
Scandinavian Airlines & SAS \\
Singapore Airlines & SIA \\
South African Airways & SAA \\
Swiss International Airlines & THA \\
TAP Air Portugal & URA \\
Thai Airways & \\
United Airlines & Tirways \\
\hline
\end{tabular}


Table 2: Governance Items

\begin{tabular}{|c|c|}
\hline No. & Annual Report: \\
\hline & Executive Background and Compensation \\
\hline 1 & Identifies top executives \\
\hline 2 & Provides background/biographical information on the top executives \\
\hline 3 & Lists the outside company boards on which the executives serve \\
\hline 4 & Discloses executive remuneration (compensation, salary, bonus, etc.) \\
\hline & Board Composition, Structure, and Processes \\
\hline 5 & States/describes board role/responsibilities. (and also committee responsibilities) \\
\hline 6 & Lists board of directors' individual members \\
\hline 7 & Provides background/biographical information on the individual board members \\
\hline 8 & Indicates board member company affiliation \\
\hline 9 & Lists the other company boards on which the board member serves \\
\hline 10 & Specifies required independence with regard to the directors (members of board) \\
\hline 11 & Identifies which board members are independent \\
\hline 12 & Specifies a required number of board members, or range. (i.e. 10-12) \\
\hline 13 & Discloses board member remuneration \\
\hline 14 & Lists the board committees \\
\hline 15 & Identifies the individual members serving on those committees \\
\hline 16 & Discloses the number of committee meetings actually held \\
\hline 17 & Discloses the percentage of committee members who actually attended the meetings \\
\hline 18 & $\begin{array}{l}\text { Discloses the number of committee meetings actually attended by each individual board } \\
\text { committee member }\end{array}$ \\
\hline 19 & Discloses the number of full board meetings actually held \\
\hline 20 & Discloses the percentage of board members who actually attended the meetings \\
\hline 21 & $\begin{array}{l}\text { Discloses the number of board meetings actually attended by each individual board } \\
\text { committee member }\end{array}$ \\
\hline 22 & Specifies the procedures for the election of Board members \\
\hline 23 & $\begin{array}{l}\text { Ownership Structure and Investor Relations } \\
\text { Provides information on investor and shareholder relations, including corporate contact } \\
\text { information }\end{array}$ \\
\hline 24 & $\begin{array}{l}\text { Discloses information on the ownership, distribution, or stock options provided to board } \\
\text { members and/or executives }\end{array}$ \\
\hline 25 & Identifies the shareholders with largest stock ownership \\
\hline 26 & Identifies external auditors \\
\hline & General Governance \\
\hline 27 & Contains a section clearly identified as "Governance" \\
\hline 28 & Indicates where the company stock is traded \\
\hline 29 & Specifies the authority upon which corporate governance is based \\
\hline
\end{tabular}


Table 3A: oneworld Alliance

Governance Items Provided ( $1=$ item provided, $0=$ item not provided)

\begin{tabular}{|c|c|c|c|c|c|c|c|c|}
\hline & EIN & AAL & BAW & CPA & FIN & IBE & LAN & QFA \\
\hline Item & $\mathbf{2 0 0 5}$ & $\mathbf{2 0 0 5} \mathbf{1 0 K}$ & $\mathbf{2 0 0 5}$ & $\mathbf{2 0 0 5}$ & $\mathbf{2 0 0 5}$ & $\mathbf{2 0 0 5}$ & $\mathbf{2 0 0 5}$ & 2005 \\
\hline 1 & 1 & 1 & $1^{*}$ & 1 & 1 & 1 & 1 & 1 \\
\hline 2 & 1 & 1 & $1^{*}$ & $1^{*}$ & $1^{*}$ & 0 & 0 & $1^{*}$ \\
\hline 3 & 0 & 1 & $1^{*}$ & $1^{*}$ & 0 & 0 & 0 & 1 \\
\hline 4 & 1 & 1 & 1 & 0 & $1^{*}$ & $1^{*}$ & $1^{*}$ & 1 \\
\hline 5 & 1 & 0 & 1 & 1 & 1 & 0 & 1 & 1 \\
\hline 6 & 1 & 1 & 1 & 1 & 1 & 1 & 1 & 1 \\
\hline 7 & 1 & 1 & 1 & 1 & 0 & $1^{* * *}$ & 0 & 1 \\
\hline 8 & 1 & 1 & 1 & 1 & 0 & 0 & 0 & 1 \\
\hline 9 & 1 & 1 & 1 & 1 & 0 & 0 & 0 & 1 \\
\hline 10 & 1 & 1 & 1 & 1 & 1 & 0 & 1 & 1 \\
\hline 11 & 1 & 1 & 1 & 1 & 1 & 0 & 0 & 1 \\
\hline 12 & 0 & 0 & 0 & 1 & 1 & 0 & 1 & 1 \\
\hline 13 & $1 * *$ & 1 & 1 & 1 & 1 & $1^{* *}$ & 1 & 1 \\
\hline 14 & 1 & 1 & 1 & 1 & 1 & 1 & 1 & 1 \\
\hline 15 & 1 & 1 & 1 & 1 & 1 & 1 & 1 & 1 \\
\hline 16 & $1^{* * * *}$ & 1 & 1 & $1^{* * * *}$ & 1 & 0 & 1 & 1 \\
\hline 17 & 0 & 1 & 0 & 0 & 0 & 0 & 0 & 0 \\
\hline 18 & $1^{* * * *}$ & 0 & 1 & 0 & 0 & 0 & 0 & 1 \\
\hline 19 & 1 & 1 & 1 & 1 & 1 & 0 & 1 & 1 \\
\hline 20 & 0 & 1 & 0 & 0 & 1 & 0 & 0 & 0 \\
\hline 21 & 1 & 1 & 1 & 1 & 0 & 0 & 0 & 1 \\
\hline 22 & 0 & 0 & 1 & 1 & 1 & 0 & 1 & 1 \\
\hline 23 & 0 & 1 & 1 & 1 & 1 & 0 & 1 & 1 \\
\hline 24 & 1 & 1 & 1 & 1 & 1 & 1 & 0 & 1 \\
\hline 25 & 0 & 1 & 1 & 1 & 1 & 1 & 1 & 1 \\
\hline 26 & 1 & 1 & 1 & 1 & 1 & 1 & 1 & 1 \\
\hline 27 & 0 & 0 & 1 & 1 & 1 & 0 & 1 & 1 \\
\hline 28 & 0 & 1 & 1 & 1 & 1 & 0 & 1 & 1 \\
\hline 29 & 0 & 1 & 1 & 1 & 1 & 0 & 1 & 1 \\
\hline
\end{tabular}

*Information only provided on executives serving on the Board of Directors

**Remuneration information provided in aggregate, not individually

****Information not provided on all Board members

****Information not provided for all committees

***** State Auditors 
Global Airline Strategic Alliances

Table 3B: Skyteam Alliance

Governance Items Provided (1 = item provided, $0=$ item not provided)

\begin{tabular}{|c|c|c|c|c|c|c|c|c|c|}
\hline & AFL & AMX & AFR & AZA & COA & CSA & DAL & KAL & NWA \\
\hline Item & 2005 & 2005 & 2005 & 2005 & $2005^{\circ}$ & 2005 & 2005 10K• & 2005 & $200510 \mathrm{~K} \bullet$ \\
\hline 1 & 1 & 1 & 1 & 0 & 1 & 1 & 1 & 1 & 1 \\
\hline 2 & 0 & 0 & 1 & 0 & 1 & 1 & 1 & 0 & 1 \\
\hline 3 & 0 & 0 & 1 & $1 *$ & 0 & 1 & 1 & 0 & 1 \\
\hline 4 & $1 *$ & 0 & 1 & 0 & 0 & $1 * *$ & 0 & 0 & 0 \\
\hline 5 & 1 & 0 & 1 & 1 & 0 & 1 & 0 & 1 & 0 \\
\hline 6 & 1 & 1 & 1 & 1 & 1 & 1 & 1 & 1 & 1 \\
\hline 7 & 1 & 0 & 1 & 0 & 1 & 1 & 1 & 0 & 0 \\
\hline 8 & 1 & 0 & 1 & 1 & 1 & 1 & 1 & 1 & 1 \\
\hline 9 & 0 & 0 & 1 & 1 & 0 & 1 & 0 & 0 & 0 \\
\hline 10 & 0 & 0 & 0 & 1 & 0 & 0 & 1 & 1 & 0 \\
\hline 11 & 1 & 1 & 0 & 1 & 0 & 0 & 1 & 0 & 0 \\
\hline 12 & 0 & 0 & 1 & 1 & 0 & 1 & 0 & 0 & 0 \\
\hline 13 & 1 & 0 & 1 & 1 & 0 & $1 * *$ & 0 & 0 & 0 \\
\hline 14 & 1 & 1 & 1 & 1 & 1 & 0 & 1 & 1 & 0 \\
\hline 15 & 1 & 1 & 1 & 1 & 1 & 0 & 1 & 0 & 0 \\
\hline 16 & $1 * * * *$ & 0 & 1 & $1 * * * *$ & 0 & 0 & 0 & 0 & 0 \\
\hline 17 & 0 & 0 & 1 & 1 & 0 & 0 & 0 & 0 & 0 \\
\hline 18 & 0 & 0 & 0 & 1 & 0 & 0 & 0 & 0 & 0 \\
\hline 19 & 1 & 0 & 1 & 1 & 0 & 1 & 0 & 0 & 0 \\
\hline 20 & 0 & 0 & 1 & 1 & 0 & 0 & 0 & 0 & 0 \\
\hline 21 & 0 & 0 & 0 & 1 & 0 & 0 & 0 & 0 & 0 \\
\hline 22 & 1 & 0 & 1 & 1 & 0 & 0 & 0 & 0 & 0 \\
\hline 23 & 1 & 0 & 1 & 1 & 1 & 1 & 1 & 1 & 0 \\
\hline 24 & 1 & 1 & 1 & 1 & 0 & 0 & 1 & 0 & 1 \\
\hline 25 & 1 & 0 & 1 & 1 & 0 & 1 & 0 & 1 & 0 \\
\hline 26 & 1 & 1 & 1 & 1 & 1 & 1 & 1 & $1 * * * * *$ & 0 \\
\hline 27 & 1 & 0 & 1 & 1 & 1 & 1 & 1 & 1 & 0 \\
\hline 28 & 1 & 1 & 1 & 1 & 1 & 0 & 1 & 1 & 1 \\
\hline 29 & 1 & 1 & 1 & 1 & 1 & 1 & 1 & 0 & 1 \\
\hline
\end{tabular}

*Information only provided on executives serving on the Board of Directors

**Remuneration information provided in aggregate, not individually

$* * *$ Information not provided on all Board members

$* * * *$ Information not provided for all committees

$* * * * *$ State Auditors

- Continental directs investors to a website for information on corporate governance and boards.

-Delta directs investors to a website for information on corporate governance and boards.

-Northwest directs investors to a website for additional information on governance and the restructuring under Chapter 11. 
Table 3C: Star Alliance

Governance Items Provided ( $1=$ item provided, $0=$ item not provided $)$

\begin{tabular}{|c|c|c|c|c|c|c|c|}
\hline & ACA & ANZ & ANA & AUA & LOT & DLH & SAS \\
\hline Item & $\mathbf{2 0 0 5}$ & $\mathbf{2 0 0 5}$ & $\mathbf{2 0 0 5}$ & $\mathbf{2 0 0 5}$ & $\mathbf{2 0 0 4}$ & $\mathbf{2 0 0 5}$ & 2005 \\
\hline 1 & 1 & $1^{*}$ & 1 & 1 & 1 & 1 & 1 \\
\hline 2 & 0 & $1^{*}$ & 0 & 1 & 0 & 1 & 1 \\
\hline 3 & 0 & $1^{*}$ & 0 & 0 & 0 & 1 & 1 \\
\hline 4 & 0 & $1^{*}$ & 0 & 1 & $1^{* *}$ & 1 & 1 \\
\hline 5 & 1 & 1 & 1 & 0 & 0 & 1 & 1 \\
\hline 6 & 1 & 1 & 1 & 1 & 1 & 1 & 1 \\
\hline 7 & 1 & 1 & 0 & 1 & 0 & 1 & 1 \\
\hline 8 & 1 & 1 & 0 & 1 & 0 & 1 & 1 \\
\hline 9 & 0 & 1 & 0 & 1 & 0 & 1 & 1 \\
\hline 10 & 1 & 1 & 0 & 0 & 1 & 0 & 1 \\
\hline 11 & 0 & 1 & 0 & 0 & 0 & 0 & 1 \\
\hline 12 & 0 & 1 & 1 & 0 & 0 & 1 & 1 \\
\hline 13 & 0 & 1 & 0 & 0 & $1 * *$ & 1 & 1 \\
\hline 14 & 1 & 1 & 1 & 1 & 0 & 1 & 1 \\
\hline 15 & 0 & 1 & 0 & 0 & 0 & 1 & 1 \\
\hline 16 & 0 & 1 & 0 & 0 & 0 & 1 & 1 \\
\hline 17 & 0 & 0 & 0 & 0 & 0 & 0 & 1 \\
\hline 18 & 0 & 1 & 0 & 0 & 0 & 0 & 1 \\
\hline 19 & 1 & 1 & 1 & 0 & 0 & 1 & 1 \\
\hline 20 & 0 & 0 & 0 & 0 & 0 & 0 & 1 \\
\hline 21 & 0 & 1 & 0 & 0 & 0 & 0 & 1 \\
\hline 22 & 0 & 1 & 0 & 0 & 0 & 1 & 1 \\
\hline 23 & 1 & 1 & 1 & 1 & 0 & 1 & 1 \\
\hline 24 & 0 & 1 & 0 & $1^{*}$ & 0 & 1 & 1 \\
\hline 25 & 0 & 1 & 1 & 1 & 1 & 0 & 1 \\
\hline 26 & 1 & 1 & 1 & 1 & 1 & 0 & 1 \\
\hline 27 & 0 & 1 & 1 & 1 & 0 & 1 & 1 \\
\hline 28 & 1 & 1 & 1 & 1 & 1 & 1 & 1 \\
\hline 29 & 0 & 1 & 1 & 1 & 1 & 1 & 1 \\
\hline
\end{tabular}


Table 3C: Continued

\begin{tabular}{|c|c|c|c|c|c|c|c|c|}
\hline & SIA & SAA & SWR & TAP & THA & UAL & USA & VRG \\
\hline Item & $\mathbf{2 0 0 4}$ & $\mathbf{2 0 0 5}$ & $\mathbf{2 0 0 4}$ & $\mathbf{2 0 0 4}$ & $\mathbf{2 0 0 5}$ & $\mathbf{2 0 0 5} \mathbf{1 0 K}$ & $\mathbf{2 0 0 5}$ & 2004 \\
\hline 1 & 1 & 1 & 1 & 1 & 1 & 1 & 1 & 1 \\
\hline 2 & 1 & $1^{*}$ & 1 & 0 & 1 & 1 & 0 & 0 \\
\hline 3 & $1^{*}$ & $1^{*}$ & 1 & 0 & 1 & 1 & $0 \bullet$ & 0 \\
\hline 4 & 1 & 1 & $1^{* *}$ & 0 & $1^{* *}$ & 1 & 1 & 0 \\
\hline 5 & 1 & 1 & 1 & 1 & 1 & 0 & 1 & 0 \\
\hline 6 & 1 & 1 & 1 & 1 & 1 & 1 & 1 & $1 *$ \\
\hline 7 & 1 & 1 & 1 & 0 & 1 & 1 & 1 & 0 \\
\hline 8 & 1 & 1 & 1 & 0 & 1 & 1 & 1 & 0 \\
\hline 9 & 1 & 1 & 1 & 0 & 1 & 1 & $0 \bullet$ & 0 \\
\hline 10 & 0 & 1 & 1 & 0 & 1 & 1 & $0 \bullet$ & 0 \\
\hline 11 & 1 & 1 & 1 & 0 & 1 & 1 & $0 \bullet$ & 0 \\
\hline 12 & 0 & 1 & 0 & 1 & 1 & 0 & $0 \bullet$ & 0 \\
\hline 13 & 1 & 1 & $1 * *$ & $1 * *$ & 1 & 1 & 1 & 0 \\
\hline 14 & 1 & 1 & 1 & 0 & 1 & 1 & 1 & 0 \\
\hline 15 & 1 & 1 & 1 & 0 & 1 & 1 & 1 & 0 \\
\hline 16 & $1 * * * *$ & 1 & 1 & 0 & 1 & 0 & $0 \bullet$ & 0 \\
\hline 17 & 0 & 0 & 0 & 0 & 0 & 0 & $0 \bullet$ & 0 \\
\hline 18 & 0 & 1 & 0 & 0 & $1^{* * * *}$ & 0 & $0 \bullet$ & 0 \\
\hline 19 & 1 & 1 & 1 & 0 & 1 & 0 & 1 & 0 \\
\hline 20 & 0 & 0 & 0 & 0 & 0 & 0 & 1 & 0 \\
\hline 21 & 0 & 1 & 0 & 0 & 1 & 0 & $0 \bullet$ & 0 \\
\hline 22 & 1 & 1 & 1 & 0 & 1 & 0 & 0 & 0 \\
\hline 23 & 1 & 1 & 1 & 0 & 1 & 1 & 1 & 0 \\
\hline 24 & 1 & 1 & $1^{* *}$ & 0 & 0 & 1 & 1 & 0 \\
\hline 25 & 1 & 1 & 1 & 1 & 1 & 1 & 1 & 0 \\
\hline 26 & 1 & 1 & 1 & 1 & $0 * * * * *$ & 1 & 1 & 1 \\
\hline 27 & 1 & 1 & 1 & 1 & 1 & 0 & $0 \bullet \bullet$ & 0 \\
\hline 28 & 1 & 1 & 1 & 0 & 1 & 1 & 1 & 0 \\
\hline 29 & 1 & 1 & 1 & 1 & 1 & 1 & 1 & 0 \\
\hline
\end{tabular}

*Information only provided on executives serving on the Board of Directors

**Remuneration information provided in aggregate, not individually

*** Information not provided on all Board members

$* * * *$ Information not provided for all committees

***** State Auditors

- Information required by this item will be set forth in IS Airways Group's definitive Proxy Statement under the captions 'Information About the Company's Board of Directors and Corporate Governance,' 'Executive Compensation,' 'Employment and Other Executive Agreements,' and “Compensation Committee Interlocks and Insider Participation” in the definitive Proxy Statement and is incorporated by reference into this Annual Report on Form 10-K (USS Airways Group, Inc. Annual Report 2005, p. 269). 
Global Airline Strategic Alliances

Table 4: Disclosure and Cross-Cultural Factor Ratings (Hofstede)

Uncertainty Avoidance, Power Distance, Individualism, Masculinity

\begin{tabular}{|c|c|c|c|}
\hline Airline & UA/PD & IND/MAS & DISCL. GROUP \\
\hline \multicolumn{4}{|c|}{ ONEWORLD } \\
\hline EIN & $35 / 28$ & $70 / 68$ & 1 \\
\hline AAL & $46 / 40$ & $91 / 62$ & 1 \\
\hline BAW & $35 / 35$ & $89 / 66$ & 1 \\
\hline CPA & $29 / 68$ & $25 / 57$ & 1 \\
\hline FIN & $59 / 33$ & $63 / 26$ & 1 \\
\hline IBE & $86 / 57$ & $51 / 42$ & 2 \\
\hline LAN & $86 / 58$ & $23 / 22$ & 1 \\
\hline QFA & $51 / 36$ & $90 / 61$ & 1 \\
\hline \multicolumn{4}{|c|}{ SKYTEAM } \\
\hline AFL & NA & NA & 1 \\
\hline AMX & $82 / 81$ & $30 / 69$ & 2 \\
\hline AFR & $86 / 68$ & $71 / 43$ & 1 \\
\hline AZA & $75 / 50$ & $76 / 70$ & 1 \\
\hline $\mathrm{COA}$ & $46 / 40$ & $91 / 62$ & 2 \\
\hline CSA & $74 / 35$ & $58 / 45$ & 1 \\
\hline DAL & $46 / 40$ & $91 / 62$ & 1 \\
\hline KAL & $85 / 60$ & $18 / 39$ & 2 \\
\hline NWA & $46 / 40$ & $91 / 62$ & 2 \\
\hline \multicolumn{4}{|l|}{ STAR } \\
\hline ACA & $48 / 39$ & $80 / 52$ & 2 \\
\hline ANZ & $49 / 22$ & $79 / 58$ & 1 \\
\hline ANA & $92 / 54$ & $46 / 95$ & 2 \\
\hline AUA & $70 / 11$ & $55 / 79$ & 1 \\
\hline LOT & $74 / 51$ & $56 / 60$ & 2 \\
\hline$\overline{\mathrm{DLH}}$ & $65 / 35$ & $67 / 66$ & 1 \\
\hline SAS & $34 / 27$ & $71 / 9$ & 1 \\
\hline SIA & $8 / 74$ & $20 / 48$ & 1 \\
\hline SAA & $49 / 49$ & $65 / 63$ & 1 \\
\hline SWR & $58 / 34$ & $68 / 70$ & 1 \\
\hline TAP & $94 / 59$ & $21 / 25$ & 2 \\
\hline THA & $64 / 64$ & $20 / 34$ & 1 \\
\hline UAL & $46 / 40$ & $91 / 62$ & 1 \\
\hline USA & $46 / 40$ & $91 / 62$ & 1 \\
\hline VRG & $76 / 69$ & $38 / 49$ & 2 \\
\hline
\end{tabular}

Group 1: Disclosure of $50 \%$ or more of the governance items

Group 2: Disclosure of less than $50 \%$ of the governance items 
uncertainty avoidance, high power distance, strong individualistic qualities, and a strong masculine orientation.

Table 5 presents a non-parametric test of the means of Hofstede's cross-cultural factors (1980) and the two disclosure groups: those that disclosed less than $50 \%$ and those that disclosed more that $50 \%$ of the governance information. The findings indicate that the intensity of disclosure is negatively correlated with uncertainty avoidance and power distance, with statistical significance at a 5\% level. Airlines from countries that ranked higher in uncertainty avoidance and power distance disclosed less governance information. This supports Gray's (1988) hypothesis that countries ranking higher in uncertainty avoidance and power distance will rank higher in secrecy. Although the correlations between disclosure and the dimensions of individualism and masculinity were not statistically significant, the findings indicate that the direction of these relationships support Gray's (1988) hypothesis that countries ranking lower in terms of individualism, and higher in terms of masculinity, will rank higher in terms of secrecy. Airlines from countries that ranked higher in terms of individualism and lower in masculinity disclosed more governance information.

\section{Table 5: Non-parametric Test of Means (Tukey Methodology) of Cross-Cultural Factors Majority versus Less-Than-Majority Disclosure}

(Majority $=$ Disclosure of $50 \%$ or More of Governance Items)

\begin{tabular}{|l|c|c|c|c|}
\hline & UA & PD & IND & MAS \\
\hline Majority & $52.43^{* *}$ & $42.43^{* *}$ & 65.14 & 54.24 \\
\hline Less-than-Majority & $72.90^{* *}$ & $55.00^{* *}$ & 52.20 & 55.50 \\
\hline
\end{tabular}

$* *=$ Statistically significant at $5 \%$ level

\section{CONCLUSION AND IMPLICATIONS}

The results of the study indicate that the intensity of governance disclosure varies across alliances and within each alliance. Although oneworld and Star Alliance presented greater intensity of governance disclosure than SkyTeam in the aggregate, there was substantial variation within each airline alliance. Perhaps governance disclosure may not be recognized, early on, as being as important in the selection of airline network alliance members as other variables. Shared complementary resources (Simon and Lane 2004) or more formal knowledge of a partner's reputation (Larson 1992) may be more important drivers. Yet, as noted above, governance information that is disclosed to the public and investor community is very much related to transparency in the netchain (Hofstede 2003) that is product and operationally focused. Thus, it appears that governance disclosure becomes increasingly important in the long-term development of strong and successful alliance relationships. A potential extension of the research, therefore, is a longitudinal study that assesses the changes in transparency and intensity of governance disclosure prior to and following entry into one of the major alliances. In addition, future research that compares the productivity of the alliances systems and the retention of alliance members might also shed light on this dimension of the issue.

The study reveals the absence of common governance disclosure standards not only across the airline alliances, but across national borders. Although there is growing interest in developing global governance standards, such as the principles developed by the Organization for Economic Cooperation and Development (OECD 2004), there are fundamental differences that inhibit easy adoption. The structure of corporate ownership, for example, varies across national borders and international regions. Significant family control and government ownership of publicly traded firms impact the shape of governance systems (Claessens et al. 1999; Arsalidou and Wang 2005). State ownership, in particular, renders Western governance mechanisms ineffectual (Mar and Young 2001) and may inhibit transparency (Tam 1999). In addition to corporate ownership and national cultural differences, formal institutions, including national law, regulations, and trading exchange rules, also impact corporate governance disclosure (Licht et al. 2005; Santema et al. 2005). Disparities 
in corporate transparency may also result from differences in institutional arrangements linked to business systems, such as emerging market, Anglo-American, and communitarian systems (Millar et al. 2005). It is clear, therefore, that the variation in governance disclosure among the airline companies is the result of broad and complex contextual differences.

A significant finding of the study is that national culture impacts corporate governance disclosure in the airline industry. It highlights the importance of understanding the role cultural factors play in corporate transparency as it impacts the evolving relationships in the airline alliance networks. This study focused on governance transparency, and did not explore financial or strategic disclosure. Future research in the study of both financial and strategic transparency in the airline alliances affords opportunities to gain a more complete understanding of corporate transparency in airline alliance systems, as well as the impact of national culture on financial and strategic disclosure.

\section{References}

Adler, P. and S. Kwon. "Social Capital: The Good, the Bad, and the Ugly.” Working Paper, Marshall School of Business, University of Southern California, 1999.

Arsalidou, D. and M. Wang. "Difficulties with Enforcing Western Standards of Corporate Governance in Asia.” European Business Law Review 16 (2), (2005): 329-342.

Afuah, A. "How Much Do Your Competitors' Capabilities Matter in the Face of Technological Change?” Strategic Management Journal 21 (3), (2000): 387-404.

Anderson, C. and G. Imperia. "The Corporate Annual Report: A Photo Analysis of Male and Female Portrayals.” The Journal of Business Communications 22 (2), (1992): 113-128.

Arthur, W. "Competing Technologies, Increasing Returns, and Lock-In by Historical Events.” The Economic Journal 99, (1989): 116-131.

Bang, H., M. Raymond, C. Taylor, and Y. Moon. "A Comparison of Service Quality Dimensions Conveyed in Advertisements for Service Providers in the USA and Korea." International Marketing Review 22 (3), (2005): 309-327.

Bekey, M. “Annual Reports Evolve into Marketing Tools.” Financial Manager 3 (1), (1990): 5060 .

Black, B. “Comparative Industrial Relations Theory: The Role of National Culture.” The International Journal of Human Resource Management 16 (7), (2005): 1137-1158.

Botosan, C. "Disclosure Level and the Cost of Capital.” The Accounting Review 72 (3), (1997): 323-347.

Bushman, R., J. Piotroski, and A. Smith. "What Determines Corporate Transparency?” Journal of Accounting Research 42 (2), (2004): 207- 252.

Christopher, T. and S. Hassan. “Culture and Corporate Governance Statement Disclosure.” Working Paper No. 0513, The Finance, Markets and Accounting Research Center, School of Accounting, Finance and Economics, Edith Cowan University, 2005.

Claessens, S., S. Djankov, and L. Lang. "Who Controls East Asian Corporations and the Implications for Legal Reform?” Working Paper No. 195, World Bank, 1999.

Coleman, J. The Foundations of Social Theory. Harvard University Press, Cambridge, Massachusetts, 1990. 
Global Airline Strategic Alliances

Cools, K. and A. Roos. The Role of Alliances in Corporate Strategy. The Boston Consulting Group, Boston, Massachusetts, 2005.

Demsetz, H. “The Theory of the Firm Revisited.” Journal of Law, Economics, and Organization 4 (1), (1988): 141-162.

Doganis, R. The Airline Industry in the 21 ${ }^{\text {st }}$ Century. Routledge, New York, New York, 2001.

Dunnett, C. "Pairwise Multiple Comparisons in the Homogeneous Variance, Unequal Sample Size Case.” Journal of the American Statistical Association 75 (372), (1980): 789-795.

Dwyer, S., H. Mesak, and M. Hsu. "An Exploratory Examination of the Influence of National Culture on Cross-National Product Diffusion.” Journal of International Marketing 13 (2), (2005): 1-27.

Eggert, A. and S. Helm. "Exploring the Impact of Relationship Transparency on Business Relationships: A Cross-Sectional Study among Purchasing Managers in Germany.” Industrial Marketing Management 32 (2), (2003): 101-108.

Galaskiewicz, J. “Interorganizational Relations.” Annual Review of Sociology 11, (1985): 281-304.

Garg, R. and J. Ma. "Benchmarking Culture and Performance in Chinese Organizations." Benchmarking 12 (3), (2005): 260-275.

Garrett. T., D. Buisson, and C. Yap. "National Culture and R\&D and Marketing Integration Mechanisms in New Product Development: A Cross-Cultural Study Between Singapore and New Zealand.” Industrial Marketing Management 35 (3), (2006): 293-307.

Grabher, G. "The Weakness of Strong Ties: The Lock-In of Regional Development in the Ruhr Area.” G. Grabher ed. The Embedded Firm: On the Socioeconomic Of Industrial Networks. London, United Kingdom: Rutledge (1993): 255-277.

Gray, S. "Towards a Theory of Cultural Influence on the Development of Accounting Systems Internationally.” Abacus 24 (1), (1988): 1-15.

Hayter, A. "A Proof of the Conjecture that the Tukey-Kramer Method is Conservative.” Annals of Statistics 12 (1), (1984): 61-75.

Hines, R. "Financial Accounting: In Communicating Reality, We Construct Reality.” Accounting Organizations and Society 13 (3), (1988): 251-261.

Hofstede, G. Culture's Consequences. Sage Publications, Beverly Hills, California, 1980.

Hofstede, G. and M. Bond. "The Confucius Connection: From Cultural Roots to Economic Growth.” Organizational Dynamics 16 (4), (1988): 4-21.

Hofstede, G. J. “Transparency in Netchains.” Paper Presented at EFITA Conference, Debrecen, Germany, 2003.

Hopwood, A. “Introduction.” Accounting, Organizations and Society 21 (1), (1996): 55-56.

Jabnoun, N. and A. Al Khafaji. "National Cultures for Quality Assurance and Total Quality Management.” Journal of Transnational Management 10 (3), (2005): 3-17.

Katz, M. and C. Shapiro. "Network Externalities, Competition and Compatibility." American Economic Review 75 (3), (1985): 424-440. 
Keasey, K. and M. Wright. "Issues in Corporate Accountability and Governance: An Editorial.” Accounting and Business Research 23 (91A), (1993): 291-303.

Kogut, B. and U. Zander. "Knowledge of the Firm, Combinative Capabilities, and the Replication of Technology.” Organization Science 3 (3), (1992): 383-397.

Koza, M. and A. Lewin. “The Co-Evolution of Strategic Alliances.” Organization Science 9 (3), (1998): 255-264.

Knutson, P. "Financial Reporting in the 1990s and Beyond: A Position Paper of the Association for Investment Management and Research.” Working Paper, University of Pennsylvania, 1992.

Krackhardt, D. “The Strength of Strong Ties: The Importance of Philos in Organizations.” N. Nohria and R. Eccles eds. Networks and Organizations. Cambridge, Massachusetts: Harvard University Press (1992): 216-239.

Kramer, C. "Extension of Multiple Range Tests to Group Means with Unequal Numbers of Replications.” Biometrics 12 (3), (1956): 307-310.

Lane, C. and R. Bachman. "The Social Constitution of Trust: Supplier Relations in Britain and Germany.” Organizational Studies 17 (3), (1996): 365-395.

Lang, M. and R. Lundholm. "Cross-Sectional Determinants of Analysts Ratings of Corporate Disclosures.” Journal of Accounting Research 31 (2), (1993): 246-271.

Larson, A. "Network Dyads in Entrepreneurial Settings: A Study of the Governance of Exchange Relationships.” Administrative Science Quarterly 37 (1), (1992): 76-104.

Lazzarini, S., F. Chaddad, and M. Cook. "Integrating Supply Chain and Network Analyses: The Study of Netchains.” Journal on Chain and Network Science 1 (1), (2001): 7-22.

Leo, J., R. Bennett, and C. Hartel. "Cross-Cultural Differences in Consumer Decision-Making Styles.” Cross Cultural Management 12 (30), (2005): 32-63.

Leonard-Barton, D. Wellsprings of Knowledge: Building and Sustaining the Sources of Innovation. Harvard Business School Press, Boston, Massachusetts, 1995.

Lere, J. and K. Portz. "Management Control Systems in a Global Economy.” The CPA Journal 75 (9), (2005): 62-65.

Lewis, J. Partnerships for Profit: Structuring and Managing Strategic Alliances. The Free Press, New York, New York, 1990.

Licht, A., C. Goldschmidt, and S. Schwartz. “Culture, Law, and Corporate Governance.” International Review of Law and Economics 25, (2005): 229-255.

Littrell, R. and L. Valentin. "Preferred Leadership Behaviors: Exploratory Results from Romania, Germany, and the UK.” The Journal of Management Development 24 (5/6), (2005): 421-443.

Malai, V. and M. Speece. "Cultural Impact on the Relationship Among Perceived Service Quality, Brand Name Value, and Customer Loyalty.” Journal of International Consumer Marketing 17 (4), (2005): 7-39.

Mar, P. and M. Young. "Corporate Governance in Transition Economies: A Case Study of Two Chinese Airlines.” Journal of World Business 36 (2), (2001): 280-301. 
McCoy, S., A. Everard, and B. Jones. "An Examination of the Technology Acceptance Model in Uruguay and the US: A Focus on Culture.” Journal of Global Information Technology Management 8 (2), (2005): 27-46.

McGinnis, M. “Lessons in Cross-Cultural Negotiations.” Supply Chain Management Review 9 (3), (2005): 9-11.

Mikhailitchenko, A. and T. Whipple. "Modeling the Effects of Culture-Related Variables on the Attitude Towards Advertising: A USA - Russia - Iran Study." Journal of East-West Business 12 (2/3), (2006): 39-59.

Millar, C., T. Eldomiaty, C. Choi, and B. Hilton. "Corporate Governance and Institutional Transparency in Emerging Markets.” Journal of Business Ethics 59 (1/2), (2005): 163-174.

Monks, R. and N. Minnow. Corporate Governance. Blackwell Publishing, Oxford, UK, 1995.

Nelson, R. "The Strength of Strong Ties: Social Networks and Intergroup Conflict in Organizations." Academy of Management of Journal 32 (2), (1989): 377-401.

Nelson, R. and S. Winter. An Evolutionary Theory of Economic Change. The Belknap Press, Cambridge, Massachusetts, 1982.

Neu, D., H. Warsame, and K. Pedwell. "Managing Public Impressions: Environmental Disclosures in Annual Reports.” Accounting, Organizations and Society 23 (3), (1998): 265-282.

Organization for Economic Cooperation and Development. OECD Principles of Corporate Governance Revised Text, Principle V. January 2004.

Oum, T., J. Park, and A. Zhang. Globalization and Strategic Alliances: The Case of the Airline Industry. Pergamon, New York, New York, 2000.

Patel, S. and G. Dallas. Transparency and Disclosure: Overview of Methodology and Study Results. Standard \& Poor's, New York, New York, 2002.

Pfeffer, J. and P. Nowak. “Joint Ventures and Interorganizational Interdependence.” Administrative Science Quarterly 21 (3), (1976): 398-418.

Rammal, H. “International Business Negotiations: The Case of Pakistan.” International Journal of Commerce and Management 15 (20), (2005): 129-141.

Rehu, M., E. Lusk, and B. Wolff. “Incentive Preferences of Employees in Germany and the USA: An Empirical Investigation.” Management Revue 16 (1), (2005): 81-99.

Ritchie, W. and K. Eastwood. "Finding the Perfect Partner: Comparing Hofstede’s Dimensions with Organizational Culture for International Joint Venture Compatibility.” Journal of Global Business 16 (32), (2005): 67-76.

Santema, S., M. Hoekert, J. Van de Rijt, and A. Van Oijen. "Strategy Disclosure in Annual Reports Across Europe: A Study of Differences between Five Countries.” European Business Review 17 (4), (2005): 352-366.

SAS Institute, Inc. SAS/STAT User's Guide, Version 8. Cary, North Carolina, 2002. 
Schepers, D. “Three Proposed Perspectives of Attitudes Toward Business' Ethical Responsibilities and Their Implications for Cultural Comparison.” Business and Society Review 111 (1), (2006): 15-37.

Simon, D. and P. Lane. “A Model of Cultural Differences and International Alliance Performance.” Journal of International Business Studies 35 (4), (2004): 306-319.

Smith, A. and E. Hume. "'"Linking Culture and Ethics: A Comparison of Accountants' Ethical Belief Systems in the Individualism/Collectivism and Power Distance Contexts." Journal of Business Ethics 62 (3), (2005): 209-220.

Sondergaard, M. "Hofstede’s Consequences: A Study of Reviews, Criticisms, and Replications.” Organization Studies 15 (3), (1994): 447-456.

Spekman, R., T. Forbes III, L. Isabella, and T. MacAvoy. “Alliance Management: A View from the Past and a Look to the Future.” The Journal of Management Studies 35 (6), (1998): 747-772.

Stanton, P. and J. Stanton. “Corporate Annual Reports: Research Perspectives Used.” Accounting, Auditing and Accountability Journal 15 (4), (2002): 478-500.

Su, S. "Cultural Differences in Determining the Ethical Perception and Decision-Making of Future Accounting Professionals: A Comparison Between Accounting Students from Taiwan and the United States.” Journal of American Academy of Business, Cambridge 9 (1), (2006): 147-159.

Swaidan, Z. and L. Hayes. "Hofstede Theory and Cross Cultural Ethics Conceptualization, Review, and Research Agenda." Journal of American Academy of Business, Cambridge 6 (2), (2005): 1016.

Tam, O. The Development of Corporate Governance in China. Edward Elgar Publishers, Chaltenham, UK, 1999.

Tukey, J. “Allowances for Various Types of Error Rates.” Unpublished IMS Address, Chicago, Illinois, 1952.

Tukey, J. “The Problem of Multiple Comparisons.” Unpublished Manuscript, 1953.

Uzzi, B. "Social Structure and Competition in Interfirm Networks: The Paradox of Embeddedness." Administrative Science Quarterly 42 (1), (1997): 35-67.

Whipple, J. and R. Frankel. "Strategic Alliance Success Factors." Journal of Supply Chain Management 36 (3), (2000): 21-28.

Yoo, B. and N. Donthu. "The Effect of Personal Cultural Orientation on Consumer Ethnocentrism: Evaluations and Behaviors of US Consumers Toward Japanese Products.” Journal of Consumer Marketing 18 (1/2), (2005): 7-44.

Zenger T. and L. Poppo. “A Knowledge-Based Theory of Organizational Boundaries.” Working Paper, John. M. Olin School of Business, Washington University St. Louis, 1999. 
Global Airline Strategic Alliances

Catherine C. Giapponi is assistant professor of Business Management. Her fields of research and teaching include business strategy, global strategic management, corporate governance and ethics in business decision making. She has published articles in the North East Journal of Legal Studies, International Journal of Risk Assessment and Management, and the Journal of Business Ethics.

Giapponi received her Sc.D in Management from the University of New Haven, an M.B.A. from the University of Connecticut, and a Bachelors of Arts from Providence College.

Carl A. Scheraga is professor of Business Strategy and Technology Management. His fields of research and teaching include transportation and international logistics, global strategic management, cross-cultural management, and the management of technology and innovation. Scheraga has published numerous articles in Transportation Research Series A, Journal of Transportation Management, Transportation Journal, Journal of the Transportation Research Forum, Journal of Public Policy and Marketing, Technology in Society: An International Journal, Journal of Banking and Finance, Global Business and Finance Review, Journal of Investing, Management International Review, International Journal of Advertising, and International Review of Economics and Finance. He also has published chapters in such volumes as Japanese Direct Investment in the United States. Trends, Developments and Issues and International Financial Market Integration. As a co-author, he has received the Transportation Research Forum Outstanding Research Paper Award in 1998 and the Aviation Research Paper Award in 1999.

Scheraga received his Ph.D. in Economics from the University of Connecticut, an M.A. in Economics, and a Sc.B in Mathematics and Engineering from Brown University. 